\title{
Predicting Counterproductive Work Behavior: Do Implicit Motives Have Incremental Validity Beyond Explicit Traits?
}

\author{
J. Malte Runge ${ }^{1}$, Jonas W. B. Lang ${ }^{1,2}$, Ingo Zettler ${ }^{3}$, and Filip Lievens ${ }^{4}$ \\ ${ }^{1}$ Department of Human Ressource Management and Organizational Psychology, Ghent \\ University, Belgium \\ ${ }^{2}$ Business School, University of Exeter, UK \\ ${ }^{3}$ University of Copenhagen, Denmark \\ ${ }^{4}$ Lee Kong Chian School of Business, Singapore Management University, Singapore
}

Author Preprint

Article was accepted for publication on 06-September-2020

To appear in:

Runge, J. M., Lang, J. W. B, Zettler, I., \& Lievens, F. (2020). Predicting

counterproductive work behavior: Do implicit motives have incremental validity beyond explicit traits? Journal of Research in Personality. https://doi.org/10.1016/j.jrp.2020.104019 


\begin{abstract}
This study extends research on the link between personality and Counterproductive Work Behavior (CWB) by investigating whether the implicit Affiliation, Achievement, and Power motives contribute to the prediction of CWB beyond basic personality traits. Employees high in Affiliation, Achievement, and Power motives may disengage from CWB because it is not rewarding and thwarts goal attainment. In Study $1(N=263)$, we found that Affiliation predicted self-rated CWB beyond traits. In Study $2(N=121)$, we found that Affiliation and Power predicted supervisor-rated CWB. Our findings thus suggest to also consider implicit motives as personality determinants of CWB.
\end{abstract}

Keywords: Counterproductive Work Behavior, Implicit Motives, Personality Traits 


\section{Predicting Counterproductive Work Behavior: Do Implicit Motives Have Incremental Validity Beyond Explicit Traits?}

An important goal of applied psychological research has long been predicting and understanding counterproductive work behavior (CWB). CWB is commonly defined as voluntary behaviors infringing important social and organizational rules, norms, and values

(Collins \& Griffin, 1998; Robinson \& Bennett, 1995; Spector \& Fox, 2005). CWB includes acts directed against other organizational members such as violence, gossip, or theft from coworkers, as well as acts directed towards the organization itself such as damaging company property, intentionally working slowly, or sharing confidential company information (Berry et al., 2007). CWB can be costly to organizations (Marcus et al., 2016). Hollinger and Davis (2002), for instance, showed that employee theft costs retailers US\$ 40.7 million every day in the United States. The costs of other forms of CWB (e.g., waste of resources, property damage) is more difficult to estimate, but researchers have calculated damage in the billions of dollars annually (Robinson \& Greenberg, 1998).

Prior research studied cognitive abilities, demographic characteristics, or personality traits as antecedents of CWB (Salgado, 2002; Zettler, 2017). Personality trait research on CWB has frequently focused on the Five-Factor Model and the HEXACO Model of Personality (e.g., Hershcovis et al., 2007; Marcus et al. , 2007; Salgado, 2002; Spector, 2011; Zettler \& Hilbig, 2010). In this study, we build on these contributions but focus on additional personality characteristics as an antecedent of CWB, namely, implicit motives. Researchers have frequently argued that in addition to traits, personality also includes implicit motives (Barrick et al., 2013; Brunstein \& Maier, 2005; Kehr, 2004; McAdams \& Pals, 2006; Spangler, 1992; Winter et al., 1998). Implicit motives are described as a predisposition to follow classes of incentives and 
goals such as Affiliation, Power, and Achievement (Emmons, 1993). Researchers have long argued that traits and implicit motives are theoretically distinct, do not necessarily correlate, and are operationalized with different assessment methods (McClelland et al., 1989; Spangler, 1992). To highlight the conceptual and empirical difference, in the context of implicit motive research researchers typically refer to traits as explicit traits. Based on the long history of explicit traits and implicit motives as distinct components of personality (Allport, 1931; McAdams, 1997; McAdams \& Pals, 2006; Murray, 1938), recent research has suggested that considering implicit motives frequently adds to the theoretical understanding in predicting important outcomes like job performance and career success (Apers et al., 2018; Lang et al., 2012; Winter et al., 1998).

The aim of the present study is to extend prior research on the link between personality and CWB (Salgado, 2002; Spector, 2011; Zettler, 2017) by investigating whether implicit motives contribute to the understanding and prediction of CWB beyond explicit traits. Building on earlier research, we test the idea that the implicit Affiliation, Achievement, and Power motives serve as a compass selecting and energizing people's behavior that is in line with their goals and disengaging from behavior that is not in line with their goals. We argue that CWB is typically not in line with goals associated with the implicit Affiliation, Achievement, and Power motives. Thus, people high in one of those motives may show less CWB because it thwarts successful motive strivings.

\section{Explicit Personality Traits and Counterproductive Workplace Behavior}

The Five-Factor (or the related Big Five) Model (McCrae \& John, 1992) is the most prevalent taxonomy to study individual differences in personality. Researchers have found considerable evidence that explicit traits from the Five-Factor Model predict CWB. Metaanalytic evidence shows that three of the Five-Factor Model traits-Emotional Stability (i.e., low 
Neuroticism), Conscientiousness, and Agreeableness - are related to different forms of CWB. Salgado (2002), for instance, found corrected correlations ranging from -.06 to -.26 between those three traits and absenteeism, accidents, deviant behavior, and turnover. Berry et al. (2007) reported that employees high in Agreeableness show less interpersonal deviance and that employees high in Conscientiousness show less organizational deviance. A different personality taxonomy that has increasingly been used to study CWB is the HEXACO Model of Personality. The HEXACO model includes Honesty-Humility, Emotionality, eXtraversion, Agreeableness, Conscientiousness, and Openness to experience. The HEXACO model is especially interesting in the context of CWB because it includes Honesty-Humility. People high in Honesty-Humility typically avoid manipulating others, do not want to break rules, are more honest, and cooperative (Ashton \& Lee, 2007). Correspondingly, meta-analyses show that Honesty-Humility is negatively linked to counterproductive (work) behavior (Pletzer, Bentvelzen, Oostrom, \& De Vries, 2019; Zettler, Thielmann, Hilbig, \& Moshagen, 2020).

Spector and Fox (2005) suggested a theoretical framework - the stressor-emotion model - explaining what role personality plays in the emergence of CWB. The core idea is that CWB occurs as a reaction to stressful work events (Berry et al., 2007) in terms of that those stressful work events induce negative emotions such as anxiety and anger that then lead to CWB. One way how personality may influence that link is that people differ in how receptive they are for negative emotions so that, for instance, people who get angry more easily show more CWB (Spector, 2011). In line with this theoretical reasoning, Hershcovis et al. (2007) reported in a meta-analysis that trait anger relates to interpersonal and organizational aggression.

The extensive literature on the link between explicit traits and CWB indicates that traits are related to $\mathrm{CWB}$. One theoretical basis for these relationships is the idea that CWB may occur 
as a reaction to social stimuli in the work environment (Spector, 2011) and that people differ in the way they react to these stimuli, suggesting the first hypothesis:

\section{Hypothesis 1: The Five-Factor and the HEXACO model explain variance in}

counterproductive work behavior.

\section{Implicit Motives}

A commonly used definition describes implicit motives as "motivational dispositions that operate outside of a person's conscious awareness and [they] are aimed at the attainment of specific classes of incentives and the avoidance of specific classes of disincentives" (Schultheiss \& Brunstein, 2010, p. 603). This definition features three specific properties of implicit motives: First, implicit motives are implicit in the sense that they operate outside of a person's conscious awareness, which means that they are not accessible through introspection.

Second, people high in an implicit motive aim to attain specific classes of incentives or goals. The classes that are typically studied are the big three implicit motives: Affiliation, Power, and Achievement (Kehr, 2004). Affiliation-motivated people want to build and maintain positive relationships with others. Power-motivated people want to influence others and search for opportunities to lead and move upwards in organizational hierarchies. Achievement-motivated people want to reach performance goals and improve their skills.

Third, implicit motives guide people towards goal attainment as a motivational force. Researchers commonly note that a core function of motivation - and implicit motives in particular-is to direct behavior towards desired goals (incentives) and away from "anti-goals" (disincentives; Carver \& Scheier, 1998; Pfaff, 1999; Schultheiss \& Brunstein, 2010; Toates, 1986). People may learn that specific cues signal the availability of a motive-specific incentive or disincentive (Brunstein et al. , 1998; McClelland, 1985; Weinberger \& McClelland, 1990). 
This link between cues and (dis)incentives may then help people to select and energize behavior to attain their goals and disengage from behavior that may thwart their goals (Spangler et al., 2014). Implicit motives affectively charge incentives and disincentives so that they are a hedonistic compass focusing on experiencing positive emotions when a goal-congruent incentive is present (Brunstein et al., 1998; Dufner at al., 2015; Fodor \& Carver, 2000; McAdams et al., 1984; Schultheiss et al., 2008).

\section{Comparing Implicit Motives to Explicit Traits}

At the same time (1930ies) and at the same place (Harvard University), two of the founding fathers of contemporary personality research - Gordon Allport and Henry Murraydeveloped competing theories of personality that strongly influence the field until today (McAdams, 1997). Murray's theory was based on motivational needs driving human behavior (Murray, 1938) and later developed into what is today known as implicit motives by the work from McClelland (1985). Allport's theory revolved around individual differences in characteristic behaviors and thoughts, based on traits (Allport, 1931). After substantial criticism on personality research in the 1960ies and 70ies (e.g., Mischel, 1968, 1973) and a decrease in corresponding research interest, trait research has recovered substantially with the emerging taxonomy of the Big Five/Five-Factor model personality traits (e.g., McCrae \& John, 1992). Research on implicit motives has recovered not that well but is far from extinct. Leading researchers of the field have frequently suggested to study personality including both traditions, explicit traits and implicit motives (Barrick et al., 2013; McAdams, 1997; McAdams \& Pals, 2006; Winter et al., 1998).

Based on both the long history and newer findings, researchers have repeatedly argued that implicit motives and traits show conceptual and empirical independence and are distinct 
components of personality (McClelland et al., 1989; Spangler, 1992; Winter et al., 1998). A first differentiation is that traits are described as "probabilistic descriptions of stable patterns of emotion, motivation, cognition, and behavior, in response to classes of stimuli that have been present in human cultures over evolutionary times" (DeYoung, 2015, p. 35), whereas implicit motives are described as cue-specific and context-dependent (Winter et al., 1998). ${ }^{1}$ Trait measures are commonly developed based on a lexical approach and researches have long emphasized the adverbial quality as the essence of traits (Allport, 1931). In this context, adverbial refers to "how" people typically behave. In comparison, implicit motives — as motivational and goal-related constructs_-refer to the "why" of behavior, i.e., to people's wishes, desires, and goals (McClelland, 1985; Winter et al., 1998).

The most crucial difference, however, may be that implicit motives operate nonconsciously, whereas traits operate (largely) consciously. This difference is reflected in the measurement, the functioning, and the predicted behavior of implicit motives and traits (McClelland et al., 1989; Spangler, 1992). Because people can observe their behavior, researchers can typically directly ask people for their traits using questionnaires. In contrast, implicit motives are defined as not accessible through introspection; thus, researchers typically measure them analyzing imaginary verbal responses to picture cues (Fodor et al., 2006; Kuhl, 2013). In line with measurement and theoretical differences, research has shown that implicit motives and explicit traits are empirically distinct with very low correlations between constructs (Lang et al., 2012; Runge \& Lang, 2019; Winter et al., 1998).

Researchers have long suggested that implicit motives and explicit traits also differ in the type of behavior that they typically predict (McClelland et al., 1989; Spangler, 1992). Implicit

\footnotetext{
${ }^{1}$ Note that personality traits are also not always conceptualized as strictly stable, but may also vary in different contexts (e.g., Lievens, Chasteen, Day, \& Christiansen, 2006; Tett \& Burnett, 2003).
} 
motives commonly predict a class of behaviors that McClelland et al. (1989) named operant behaviors. The core idea is that operant behaviors are generated spontaneously-i.e., an organism is operating on the environment (i.e., taking action) rather than responding — and it is difficult to specify the stimuli in the environment that elicited the behavior. Operant behaviors typically occur in the presence of activity incentives. Activity incentives are characteristics of a behavior or task itself (Spangler et al., 2014). Showing a behavior in the presence of an activity incentive directly reinforces someone high in the respective implicit motive. Activity incentives for Achievement include situations in which a goal can be set independently, for Affiliation includes situations in which relationships can be enjoyed, and for Power situations in which others can be influenced (Spangler et al., 2014). Implicit motives may thus predict spontaneous behavioral trends in situations with specific activity incentives.

In contrast, explicit traits typically predict respondent behavior in which an organism responds to known stimuli and immediate choices (McClelland et al., 1989). Respondent behaviors may show in response to social incentives. Social incentives are described as external rewards and expectations and include norms and demands from outside the person—-for instance, supervisors, co-workers, or the organization in a broader sense (Spangler et al., 2014). A social Achievement incentive is a goal set by others, social Affiliation incentives include expectations directly rewarding collaborative behavior, and a social Power incentive includes direct responses to a power-related event or explicit group norms. Traits thus typically predict immediate behavior with specific explicit social incentives.

\section{Implicit Motives and Counterproductive Work Behavior}

In this study, we investigate the idea that CWB may not only occur as a reaction to specific environmental stimuli but also in situations with unclear stimuli-that are typically 
predicted by implicit motives. People high in an implicit motive select behavior leading to positive emotional experiences related to the motive and do not select behavior thwarting their goals (Dufner et al., 2015; Stanton et al. , 2010). CWB may not be a type of behavior leading to positive emotional experiences related to one of the classes of implicit motives (i.e., Affiliation, Achievement, and Power), and therefore CWB may also not be selected and energized by employees high in one of those implicit motives. On the contrary, CWB may actually thwart the goals related to one of those implicit motives and people high in one of them may therefore disengage from CWB. For instance, Affiliation-motivated employees might want to build positive relationships with others, but harming others goes directly against this aim. Indeed, research has shown that coworkers may have negative impressions of employees who engage in CWB (Farley, 2011), which makes it difficult to build positive relationships.

As described above, implicit motives are typically linked to activity incentives and commonly predict operant behavior. Spector (2011) described that CWB is often-in addition to planned and controlled acts-immediate, reactive, and impulsive in response to events in the work environment, which may also include situations with activity stimuli. Employees high in the implicit Affiliation, Achievement, or Power motive may feel displeasure when they show CWB because it thwarts their goals and, consequently, they learn that CWB is connected to motive-specific activity disincentives. For instance, an employee high in the implicit Affiliation motive showing bullying behavior may experience negative emotions because bullying is not in line with their affiliative goals. They learn to disengage from those behaviors to successfully strive for their motivational goals. In line with this idea, researchers have shown that people high in an implicit motive have good self-control abilities when their motivational goal is threatened, (Gröpel \& Kehr, 2014); and, indeed, self-control may play an important role in disengaging from 
CWB (Marcus \& Schuler, 2004). In reaction to stressful situations without explicit social incentives, CWB likely happens when people lack the implicit motives to help regulate their behavior. When people are high in the Affiliation, Achievement, or Power motive, they may be more likely to curb CWB because it thwarts the goals associated with those motives. People low in one of those motives may not select their behavior based on underlying motivational goals, and when they would show CWB it would not thwart a goal. People high in the Affiliation, Achievement, or Power motive may therefore be less likely to engage in CWB.

In contrast to implicit motives, explicit traits are linked to respondent behavior and social incentives. A widely studied CWB-model is based on reactive aggression (Spector \& Fox, 2005) in which employees react to specific provocations from the environment. Provocations are typically visible in the context of an explicit stimulus, connected to social incentives and disincentives. For instance, an employee may feel treated unfairly because they receive less pay compared to a colleague who is in a similar role. People high in trait negative emotionality are then more likely to react with CWB (Spector, 2011).

We suggest that implicit motives and explicit traits may be linked to CWB in different situations and with different (dis)incentives. Spontaneous and operant behaviors with activity stimuli are typically predicted by implicit motives and less by traits (Spangler, 1992). Therefore, we suggest that implicit motives may have incremental predictive validity above explicit traits in the prediction of CWB, resulting in the second hypothesis:

\section{Hypothesis 2: Employees' implicit motives improve the prediction of counterproductive} work behavior beyond personality traits.

In the following sections, for all three implicit motives we theorize how CWB may interfere with successful motive thriving, and, consequently, why they may act as a buffer for CWB. 


\section{The Implicit Affiliation Motive and Counterproductive Workplace Behavior}

The implicit Affiliation motive is defined as a concern to establish, maintain, or restore positive emotional relationships with other people or a group (Koestner \& McClelland, 1992). People high in Affiliation try to actively find affiliative activities, spend their time interacting with other people (McClelland, 1985), and try to maintain the goodwill of their interaction partner (McClelland, 1975). They avoid conflict (Exline, 1962), are sympathetic towards others (Koestner \& McClelland, 1992), and adapt their social behavior to achieve a peaceful relationship (Walker \& Heyns, 1962). Historical and experimental research also showed that Affiliation-motivated people facilitate concessions and compromises to reach peaceful solutions in international crises (Langner \& Winter, 2001). Taken together, people high in the implicit Affiliation motive invest their resources into positive emotional relationships with others.

Behaviors and goals of Affiliation motivated employees typically do not include behaviors that harm others. On the contrary, CWB may actually lead to need frustration for Affiliation-motivated employees. Engaging in negative gossiping, bullying, or violence may not satisfy Affiliation-related needs. Research has found that high-frequency gossipers are liked less (Farley, 2011), as well as that bullies in school are rejected by most peers (Pellegrini et al., 1999) and are more likely to be isolated in teams (Coyne et al., 2004). Research has also found that positive affiliative experiences lead to more positive affect for people high in the implicit Affiliation motive (Dufner et al., 2015). Social relationships are important for people high in the implicit Affiliation motive and CWB may thwart that goal. People high in the implicit Affiliation motive generally value positive relationships, devalue conflict, and possible consequences of CWB may conflict with those goals. Therefore, we expect a negative relationship between the implicit Affiliation motive and CWB. 
Hypothesis 3: People high in the implicit Affiliation motive show less CWB compared to people low in the implicit Affiliation motive.

\section{The Implicit Power Motive and Counterproductive Workplace Behavior}

The core of the Power motive is having an impact on their environment or other people. Researchers studying implicit motives suggested that the implicit Power motive has a dual nature, it can inspire great leaders, but also lead to corruption and destruction (McClelland, 1970; Winter, 2016; Zurbriggen, 2000). The different ways of how Power can be enacted have been called socialized and personalized implicit Power. The socialized implicit Power motive is characterized by an implicit desire to help and influence others, to lead others, to maintain reputation, or be in a mentorship role. Personalized implicit Power — or need for dominance—is also concerned with having an impact on others; however, typically through profligate and impulsive behavior (Hofer et al., 2010; Winter, 1973). Researchers pointed out that the key difference is that people high in the socialized implicit Power motive avoid negative effects on others and enact power only in socially accepted ways (Winter, 1973; Zurbriggen, 2000). The distinction between socialized and personalized implicit Power is, to our knowledge, new in the field of industrial and organizational psychology, where power is typically conceptualized as either being part of a role (position power) or part of personality (personal power; Pfeffer, 1981; Yukl \& Falbe, 1991). In difference to people high in the Affiliation motive that strive for positive relationships independent of hierarchies, people high in the socialized Power motive enjoy influencing others and strive for a higher position in terms of a vertical relationship. In this study, we focus on socialized Power as an implicit motive driven by activity incentives, orienting and guiding employee's Power strivings into positive and socially accepted behavior. We are interested in how implicit motives can serve as a buffer and direct employees away from CWB. 
We suggest that socialized implicit power can act as a buffer similar to the implicit Affiliation motive. For the remainder of the manuscript, we use the term "implicit Power" as a short form for the implicit socialized Power motive.

In an organizational context, Power-motivated employees search for situations in which they can help other employees, take the lead, and look for opportunities to reach higher and more prestigious positions in an organization. Researchers suggested that charismatic leaders have a high implicit Power motive (House \& Howell, 1992) and found evidence in a study linking the implicit Power motive of US presidents to charismatic leadership behavior (House et al., 1991). The implicit Power motive also predicted socially responsible behavior over 10 years (Winter et al., 1981).

A central characteristic that people look for in a leader is integrity and trustworthiness (Lord et al., 1984). Whether or not someone is perceived as a credible leader may depend, among other factors, also on perceived integrity. Therefore, Hogan and Kaiser (2005, p. 173) wrote that the most important question one asks of a potential leader is "Can we trust you not to abuse the privilege of authority?”. A leader high in the implicit Power motive is striving to be a trustworthy leader, motivated by influencing and positively impacting others, empowering and supporting followers, and not by harming them or the organization. CWB encompasses behavior going against those goals and wishes, and employees high in the implicit Power motive may thus disengage from it. We therefore expect that employees high in the implicit Power motive show less CWB. Employees who are low in the implicit Power motive typically do not strive to be a trustworthy leader or seek a higher position. Because they do not strive for those goals, they may be less motivated to disengage from CWB. We therefore expect those employees low in implicit 
Power motivation to engage in CWB. Put together, we expect a negative relationship between the implicit Power motive and CWB.

Hypothesis 4: People high in the implicit Power motive show less CWB compared to people low in the implicit Power motive.

\section{Implicit Achievement Motivation and Counterproductive Workplace Behavior}

The implicit Achievement motive has been defined as a concern to improve one's performance, to do well in challenging tasks, and to meet a standard of excellence (McClelland et al., 1989). Employees high in the implicit Achievement motive get satisfied by mastering tasks independently in Achievement-related situations and are concerned with truly improving their skills and performance (McClelland, 1985). For people high in the implicit Achievement motive, reaching a goal using cheating strategies (a form of CWB) may not come with satisfaction, because it does not feel like a real achievement or learning progress. CWB also includes wasting time at work, poor attendance, poor working quality, and intentionally slow or sloppy work (Cullen \& Sackett, 2003)—behaviors that may thwart achievement goals. People high in the implicit Achievement motive may therefore be less likely to choose and energize behavior such as working slow and poor. They further seek, benefit, and learn from performance feedback (Fodor \& Carver, 2000; McClelland, 1985). Although the implicit Achievement motive is not social in itself (in contrast to implicit Affiliation and implicit Power), contact with other people may still be relevant for optimal performances. Employees engaging in CWB may receive less help and feedback from an organization. Having less support would make it more difficult for them to successfully strive for their Achievement motive. Therefore, employees high in the implicit Achievement motive may show less CWB. 
Hypothesis 5: People high in the implicit Achievement motive show less CWB compared to people low in the implicit Achievement motive.

\section{The Present Studies}

Researchers have long argued that CWB ratings can differ depending on the rating source. Self-ratings and supervisor ratings may cover different aspects of CWB (Berry et al., 2012). In this paper, we present two studies with different rating sources. In the first study, ${ }^{2}$ we used employee self-ratings for CWB. An advantage of CWB self-ratings is that CWB may include covert behaviors so that the only complete source of employee engagement in CWB is the employee themselves (Berry et al., 2012). In the second study, we asked supervisors to rate employee CWB. Supervisor ratings have the advantage that they seem less likely to underreport (observed) CWB due to social desirability biases and also ensure that predictor and criterion measures come from different sources (Berry et al., 2012). Studying CWB with self- and supervisor reports combines the advantages of both approaches.

\section{Study 1}

\section{Method}

\section{Participants and Procedure}

The participants in the first study were a diverse sample of German employees from various organizations and occupational backgrounds. Three research assistants contacted people they knew personally and through social networking sites to participate in the study. In addition, they went to public offices and shops in city centers of larger cities and asked employees whether they wanted to participate in the study. The instructions asked the employees to fill out a

\footnotetext{
2 The data overlap with Lang et al. (2012). While Lang et al. (2012) focused on the link between implicit motives and explicit traits with task and contextual performance $(N=241)$ and did not study $\mathrm{CWB}$, the present paper linked implicit motives and explicit traits to self-report CWB data $(N=263)$.
} 
questionnaire booklet and return it using a stamped return envelope. Participants could provide their e-mail addresses to receive a summary of the findings of the study via e-mail. No further rewards were offered. A total of 520 employees agreed to participate. We received 272 questionnaires back. A total of 263 questionnaires provided complete information on the study variables. The employees (158 female, 105 male) were between 18 and 69 years of age $(M=$ $35.25, S D=10.88)$, worked $M=36.48 \mathrm{hrs}$ per week on average $(S D=12.04 \mathrm{hrs})$, and had been in their organizations for an average of $M=7.67$ years $(S D=9.33$ years $)$. We asked the participants to indicate their job with an open question. We provide an overview of the job types in the Appendix.

\section{Measures}

Implicit Motives. To measure implicit motives, researchers developed picture-based procedures where respondents write a story that gets coded for motivational content (McClelland et al. , 1953; Morgan \& Murray, 1935). We measured implicit motives with the Operant Motive Test (OMT; Kuhl, 2013). The OMT is a modernized version of earlier picture-based measures like the Thematic Apperception Test (Morgan \& Murray, 1935) and the Picture Story Exercise (McClelland et al., 1953; Winter, 1994) with more pictures. In the OMT, respondents see 15 pictures with ambiguous social scenes (see Runge et al., 2016, for an example). Respondents are told to imagine a story that spontaneously comes to their mind when they see the pictures. Respondents are then instructed to indicate the main person of their story (in pictures with more than one person) and answer the following two questions "What is important for the person in this situation and what is the person doing?" and "How does the person feel and why does the person feel this way?". The verbal responses are then coded into Affiliation, Achievement, and Power motives and non-motivational content based on the criteria of the OMT coding manual 
(Kuhl, 2013). Implicit motive coding systems typically consist of several different motive categories (e.g. Smith, 1992; Winter, 1994). The OMT includes 15 categories (five for each of the three motives) representing different ways of motive enactment. Researchers using the OMT have sometimes relied on a broad motive definition including all categories for a motive. Frequently, however, researchers used more narrow definitions focusing on stories about attaining goals in a positive and motivated way as the core of a motive and excluded categories for stories focusing on unsuccessful motive striving. This narrower focus on motivated goal attainment follows the theoretical idea that positive emotions connected to attaining a goal help people to select behavior. This standard approach also matches closely with the conceptualization of implicit motives that motivate operant behavior based on activity incentives (McClelland et al., 1989; Spangler et al., 2014). In contrast, motive categories focusing on unsuccessful motive striving (such as feeling lonely for Affiliation) are not about individuals high in an implicit motive being reinforced in behavior based on activity incentives. Failure in motive striving might signal that a motivational goal has not been met (one could suspect that this goal may be of some relevance), but it does not indicate that the individual would also show behavior oriented towards goal attainment — and that this behavior would be directly reinforced and experienced as rewarding. Based on these theoretical considerations and recent developments in IRT research (Lang, 2014), psychometric OMT research provided evidence for the construct validity and reliability on motives conceptualized as a narrow approach with three categories for each motive (Lang et al., 2012; Runge et al., 2019; Runge et al., 2016; Schüler et al., 2015). In line with this standard approach, we combined the three categories for each motive capturing stories about attaining goals in a positive and motivated way (encounter, sociability, and networking for Affiliation; leadership, recognition, and self-assertion for Power; flow, a 
standard of excellence, and coping with failure for Achievement). A detailed description of the coding categories and procedure is provided by Kuhl (2013).

The responses were coded by a trained expert coder who received extensive coder training and reached a high agreement with coworkers of the original author of the OMT. To analyze the inter-rater agreement, two trained student assistants coded a subsample of the responses. The first assistant coded 65 and the second 81 OMT responses. To determine the rater agreement, we calculated Gwet's $A C_{1}$ statistic (Gwet, 2008a, 2008b). Gwet's $A C_{1}$ is an improved version of Cohen's Kappa. Rater agreement between the main coder and the first assistant was .87 for Affiliation, .76 for Power, and .83 for Achievement, and rater agreement between the main coder and the second assistant was .89 for Affiliation, .76 for Power, and .90 for Achievement.

Personality. We measured personality with the German adaptation of the Big Five Inventory (John et al. , 2008), a 45-item measure. Participants responded using a 5-point Likerttype scale ranging from (1) totally disagree to (5) totally agree. Cronbach's $\alpha$ was .85, .78, .68, .80 , and .75, for Extraversion, Conscientiousness, Agreeableness, Neuroticism, and Openness, respectively.

Counterproductive Work Behavior. CWB was rated by employees using the workplace deviance scale introduced by Bennett and Robinson (2000). The scale consists of 19 items describing deviant behaviors such as making fun of someone at work or working intentionally slowly. Respondents indicated on a 7-point Likert scale ranging from 1 (never) to 7 (daily) the extent to which they had engaged in each of the behaviors in the last year. The CWB score had a Cronbach's $\alpha$ of .80 .

\section{Results}


Descriptive Statistics and Correlations. Table 1 provides descriptive information and intercorrelations of the variables in Study 1. CWB correlated significantly and negatively with Conscientiousness, Agreeableness, and the implicit Affiliation motive. In line with previous findings, correlations between implicit motives were low. Also in line with previous research (Greco, O’Boyle, \& Walter, 2015), CWB ratings had a relatively low mean.

Multiple Regression Analyses. To test our hypotheses, we conducted multiple regression analyses to predict CWB with the five personality traits and the three implicit motives. All analyses were conducted using R. Table 2 (upper part) shows the multiple regression analyses testing our hypotheses for Study 1. To examine our four hypotheses, we first fitted a model including only traits (Model 1). We then fitted a model including only the three implicit motives (Model 2). Finally, we fitted a third model including both traits and implicit motives (Model 3). We started our analyses with Hypothesis 1 stating that traits explain considerable variance in CWB. Model 1 (traits only) explains a substantial amount of variance $\left(R^{2}=.16 ; F(257)=9.73\right)$, which is typically considered as a medium effect (Cohen, 1988). In this model, Agreeableness $(ß=-.25 ; t=-4.16 ; p<.001)$ and Conscientiousness $(ß=-.31 ; t=-$ 5.15; $p<.001)$ were significant predictors of CWB. Hypothesis 1 was thus supported. Hypothesis 2 stated that implicit motives explain additional variance in CWB over explicit traits. To examine this, we compared the explained variance of the three models using multiple $R^{2}$ values. As indicated in Table 2 , results showed that the personality only model (Model $1 ; R^{2}=$ .16) explained more variance than the implicit motives only model (Model $2 ; R^{2}=.05$ ). When implicit motives were added to the personality model, explained variance (Model $3 ; R^{2}=.20$ ) increased significantly $(F(257)=4.02 ; p=.001)$, with the increase being in between a small and medium effect size (Cohen, 1988). Thus, Hypothesis 2 was also supported. Hypothesis 3 stated 
that Affiliation motivated employees show less CWB. In both Model $2(\beta=-.25 ; t=-3.67 ; p<$ $.01)$ and Model $3(B=-.20 ; t=-3.12 ; p<.01)$, Affiliation was a significant predictor of CWB, supporting Hypothesis 3. Hypothesis 4 stated that Power is negatively related to CWB. In both Model $2(\beta=-.10 ; t=-1.48 ; p=.14)$ and Model $3(\beta=-.05 ; t=-0.75 ; p=.45)$, Power was not related to CWB. Hypothesis 4 was thus not supported. For Hypothesis 5, we were interested in the relationship between the Achievement motive and CWB. Results showed no relationship between these constructs in both Model $2(\beta=.06 ; t=1.06 ; p=.29)$ and Model $3(\beta=.08 ; t=$ $1.38 ; p=.17)$. Thus, Hypothesis 5 was also not supported.

\section{Study 2}

\section{Method}

\section{Participants and Procedure}

The participants in this study were a diverse sample of Dutch and German employees and their respective supervisors from different organizations with various occupational backgrounds. Three research assistants contacted people they knew personally or through social networking sites, as well as employees in public offices and shops. We first asked employees whether they wanted to participate in a scientific study on personality and workplace behavior. If they agreed, we then directly asked the supervisor to participate. If both agreed to participate, we gave them an employee and a supervisor questionnaire booklet. The research assistants either gave the supervisor questionnaire booklet directly to the supervisor and collected the response, or supervisors received a stamped return envelope. When the response was not personally collected by a research assistant, we asked participants to return the questionnaire via mail using stamped return envelopes. Participants had the option to provide their email addresses to receive a summary of the findings of the study via e-mail. No other rewards were offered for participation 
in the study. We received envelopes from 128 employees and 125 supervisors, and 121 employee-supervisor dyads were complete. The employees ( 72 female, 45 male; 4 did not indicate their gender) in these dyads were between 20 and 61 years of age $(M=34.36, S D=$ 11.14 years), worked $M=37.39$ hours per week on average ( $S D=10.07$ hours), and had been in their organizations for an average of $M=5.74(S D=9.60)$ years. Additionally, we asked the participants to indicate their job with an open question and provide an overview of the job types in the Appendix. Supervisors indicated that they had been working with their employees for on average of $M=4.02(S D=6.05)$ years. Most of the supervisors reported that they had frequent interactions with their employees ( $n=88$ at least once a day; $n=28$ at least once a week).

\section{Measures}

Implicit Motives. As in Study 1, we used the OMT to measure implicit motives. The responses were coded by three student assistants that received extensive coder training. To analyze the rater agreement, the first author coded 20 of all OMTs for each student assistant. Gwet's $A C_{1}$ was .94 for Affiliation, .88 for Power, and .91 for Achievement for the first rater, .88 for Affiliation, .94 for Power, and .91 for Achievement for the second rater, and .96 for Affiliation, .89 for Power, and .93 for Achievement for the third rater.

Personality. We measured the six HEXACO personality dimensions with the 100-item version of the HEXACO Personality Inventory-Revised (Lee \& Ashton, 2018; Moshagen, Thielmann, Hilbig, \& Zettler, 2019). Participants responded using a 5-point Likert-type scale ranging from (1) totally disagree to (5) totally agree. Internal consistency was estimated via Cronbach's $\alpha$ and was $.87, .87, .83, .83, .80$, and .81 , for Honesty-Humility, Emotionality, Extraversion, Agreeableness, Conscientiousness, and Openness to Experience, respectively. 
Counterproductive Work Behavior. As in Study 1, CWB was measured using the scale by Bennett and Robinson (2000). However, in contrast to Study 1 where the employees selfreported on their CWB, in Study 2 the employees' supervisors filled out the scale about the employees' CWB. Specifically, we asked the supervisors "to what extent do the following statements apply to the rated person" and adapted the items grammatically so that they fit the supervisor rating (e.g., "The rated person acted rudely toward someone at work"). In Study 2, Cronbach's $\alpha$ of the scale was .92 .

\section{Results}

Descriptive Statistics and Correlations. Descriptive information and intercorrelations for Study 2 are provided in Table 3. CWB correlated significantly and negatively with the implicit Affiliation motive. Correlations between traits and motives were low. The mean for CWB was low; however, the mean for self-reported CWB (Study 1) was higher than for supervisor-rated CWB (Study 2). This finding is consistent with literature suggesting that supervisors may have less opportunity to observe employees engaging in CWB (Berry et al., 2012).

Multiple Regression Analyses. We analyzed the data from Study 2 using the same strategy as in Study 1. Table 2 (lower part) shows the multiple regression analyses testing our hypotheses for Study 2. We found no support for Hypothesis 1. For Hypothesis 2, the analyses showed that the personality only model (Model $1 ; R^{2}=.02$ ) —a small effect size—explained less variance than the implicit motives only model (Model $2 ; R^{2}=.08$ ), which showed a small to medium effect size (Cohen, 1988). When implicit motives were added to the personality model, explained variance increased significantly (Model 3; $\left.R^{2}=.11 ; F(114)=3.75 ; p=.01\right)$. Thus, Hypothesis 2 was also supported in Study 2. Testing Hypothesis 3, the implicit Affiliation 
motive was a significant predictor of CWB in Model $2(\beta=-.19 ; t=-2.05 ; p=.04)$ and Model 3 $(ß=-.19 ; t=-2.16 ; p=.02)$, supporting Hypothesis 3. For Hypothesis 4, we found that Power was a significant predictor for CWB in Model $2(\beta=-.20 ; t=-2.21 ; p=.03)$ and Model $3(\beta=-$ $.22 ; t=-2.29 ; p=.02$ ), thus supporting Hypothesis 4 (which was not supported in Study 1). Results for Hypothesis 5 again showed no relationship between Achievement and CWB in both Model $1(ß=-.15 ; t=-1.60 ; p=.11)$ and Model $2(ß=-.16 ; t=-1.74 ; p=.09)$.

\section{Supplemental Analysis}

In the first supplemental analysis, we studied personalized Power and CWB. Compared to socialized implicit Power, personalized implicit Power may have a different relationship with CWB. People high in personalized implicit Power typically show profligate and impulsive behavior (Hofer et al., 2010; Winter, 1973, 2016), and personalized implicit Power is positively related to antisocial outcomes (Magee \& Langner, 2008). The OMT also measures personalized Power-however, less detailed (only one coding category, dominance) compared to socialized Power, and the response frequency is typically lower compared to socialized Power.

Correspondingly, psychometric research provided strong support for construct validity and reliability of socialized Power (Runge et al., 2019, 2016), but not for personalized Power. Nevertheless, we exploratively analyzed whether personalized Power measured with the OMT predicts CWB. Employees high in personalized implicit Power may experience some CWB as rewarding and useful to attain their goals. For instance, slandering to harm a competitor for a promotion may come with positive emotions for employees high in personalized implicit Power. One might therefore expect a positive relationship between personalized implicit Power motivation and CWB. We included personalized Power as additional predictor in Model 3 and 
found no support for any relation between this construct and CWB in Study $1(B=.01 ; t=0.12$; $p=.90)$, nor in Study $2(ß=.02 ; t=0.61 ; p=.54)$.

In our second supplemental analysis, we studied potential interactions between traits and motives. Researchers have repeatedly argued that —although theoretically distinct—implicit motives and traits may interact and complement each other (Lang et al., 2012; Winter et al., 1998). The underlying idea is that explicit traits may provide habits or traits that may enable —or challenge - implicit motives to influence behavior. For the present study, we developed hypotheses suggesting main effects of implicit motives on CWB based on the idea that employees chose behavior that feels rewarding. However, channeling effects may also be relevant for CWB. For instance, the effects of implicit measures of aggression on CWB may be shaped by explicit aggression (Bing et al., 2007; Uhlmann et al., 2012). In analogy to earlier work on channeling and implicit motives (Lang et al., 2012; Winter et al., 1998), we therefore exploratively tested channeling effects of Extraversion on the implicit Power/CWB and the implicit Affiliation/CWB links. Extraversion is a personality trait that is typically most closely linked to interpersonal relationships and is thus likely to channel effects of social implicit motives. To test these ideas, we added interaction terms between implicit Affiliation motive and Extraversion, and between implicit Power motive and Extraversion to Model 3. Results provided no evidence for an implicit Affiliation/Extraversion channeling effect, Study $1: \beta=.09, t(253)=$ 1.56; Study 2: $\beta=-.08, t(253)=-0.79$, nor a Power/Extraversion channeling effect, Study 1: $\beta=$ $-.06, t(253)=-1.10 ;$ Study $2: \beta=-.09, t(253)=0.98$. A possible explanation is that employees high in the implicit Affiliation or Power motive disengage from CWB and that this main effect makes it difficult to find interaction effects.

\section{Discussion}


The general aim of this study was to advance the literature on CWB by considering implicit motives in addition to traits as a key albeit unexplored antecedent. We specifically investigated whether the implicit Affiliation, Achievement, or Power motives predict CWB in addition to traits in two studies with broad occupational samples measuring CWB with selfratings in the first study and supervisor ratings in the second study. Across the studies, we found that some implicit motives predict CWB in addition to explicit traits. More specifically, we found that employees high in the implicit Affiliation motive showed less CWB in both studies, and that employees high in the implicit Power motive showed less CWB in the second study.

\section{Implications}

Previous studies on other work-related outcomes found that implicit motives predict career success (Spangler, 1992; Winter et al., 1998), entrepreneurial success (Rauch \& Frese, 2007; Wainer \& Rubin, 1969), income (Apers et al., 2018), and task and contextual performance in interaction with traits (Lang et al., 2012). Thus far, most research on the prediction of CWB has focused on explicit traits (Hershcovis et al., 2007; Salgado, 2002; Zettler, 2017). The two studies in this paper found that implicit motives may also play a role in predicting CWB. This finding is in line with arguments (Winter et al., 1998) that implicit motives - in the tradition of Murray (1938) and McClelland (1984) — may be an important personality characteristic next to traits in the tradition of Allport (1931). These findings complement previous research on individual difference variables on CWB by also considering implicit motives. Therefore, conclusions regarding the role of personality in CWB may need to be extended. In a broader context, this study contributes to a stream of literature using implicit measures to predict CWB, such as the conditional reasoning test (Bing et al., 2007; James \& LeBreton, 2012). 
In this study, we found evidence that the implicit Affiliation and Power motives may buffer CWB, based on the idea that people high in one of those motives do not show CWB because it is associated with disincentives and thwarts successful motive striving. A key difference between traits and motives is that they predict different types of behavior (McClelland et al., 1989). Traits typically describe respondent behavior in response to known stimuli and immediate choices, such as CWB in response to an open provocation or as a planned act (Spector, 2011). Implicit motives, by contrast, typically predict operant behavior with activity stimuli that are generated spontaneously (Spangler, 1992). Based on the idea that traits and motives predict different behavior as well as the findings in this study, one could conclude that CWB occurs not only in response to clear social stimuli but may also happen in unclear, unplanned, and unstructured situations - so that this (kind of) CWB is predicted by implicit motives rather than traits. For instance, CWB like gossiping might occur not exclusively as a planned and targeted act or in response to an explicit provocation, but also without a clearly visible reason. We found that both implicit motives and explicit traits predict CWB when the other was considered. A possible interpretation may be that explicit traits and implicit motives indeed predicted operant and respondent CWB, respectively. This interpretation is, however, speculative because we did not distinguish between operant and respondent CWB. Future research may consider distinguishing between operant and respondent CWB.

We found in both studies, with self- and supervisor-rated CWB, that the implicit Affiliation motive buffers CWB. This finding is supportive of theoretical ideas and qualitative findings that social motives and interpersonal interaction can play an important role at work (Wrzesniewski et al. , 2003). It is also in line with previous research studying CWB and traits that are important in social situations. Specifically, researchers found evidence that 
Agreeableness and Emotional Stability predict CWB (Berry et al., 2007; Hershcovis et al., 2007), and we replicated these findings for Agreeableness in the first study. Both traits are conceptually linked to the Affiliation motive (Barrick et al., 2013). We conclude that both theoretical ideas and empirical studies support the notion that employees who strive for Affiliation goals are typically not harming coworkers or the organization they work in.

We did not find any relationship between the implicit Achievement motivation and CWB. The implicit Achievement motive has no social focus and does not require the presence of others or the organization, in contrast to the implicit Affiliation and Power motives. Research has shown that a major situational predictor of CWB is rooted in interpersonal conflicts, as well as perceptions of organizational and interpersonal injustice (Berry et al., 2007; Hershcovis et al., 2007). As the interpersonal context is less important for the implicit Achievement motive, it seems plausible that we did not find any relationship with CWB.

In the first supplemental analysis, we found no support for the link between personalized implicit Power motive and CWB. A potential explanation is that the OMT has no special focus on personalized Power. Because there are strong theoretical considerations for this link (Winter, 1973, 2016; Zurbriggen, 2000), future research should study the link between CWB and personalized implicit Power motive with an improved measure of the personalized implicit Power motive. A potential approach may be to develop a specialized motive test similar to the Heckhausen measure (Heckhausen et al., 1985) that focusses on differentiating facets of the implicit Achievement motive. For a specialized need for Power measure, one would first need to develop a differentiated coding scheme including various ways of how personalized Power could be expressed in stories. In a second step, one would need to develop a picture set including more pictures with personalized Power themes to increase the response frequency. 
A practical implication of our study is that implicit motives may be useful in personnel and selection contexts. A potential advantage of implicit motive measures is that they may prove more difficult to fake in comparison to Likert-scale questionnaires. A potential challenge is that scoring implicit motives is a time-intensive procedure, especially in large scale screenings for selection purposes. Researchers are, however, working on solutions to reduce the resources needed to score implicit motives. One approach develops scoring algorithms using existing data to realize machine-based scoring (Schultheiss, 2013; Spangler et al. , 2019). Another recently suggested approach — the Motive Self-Categorization test—showed that respondents can indicate their motives in the stories they write and the scores showed convergent validity with expert scorings (Runge \& Lang, 2019). These two different approaches show promising alternatives to time-consuming expert coders that may allow implicit motives to be measured also in applied contexts in the future.

\section{Limitations}

As a first limitation, both of our studies used cross-sectional research designs. Accordingly, it is not possible to infer causality. Future research should thus also explore the effects of implicit motives on CWB over time. Another potential limitation of the investigation is that Study 1 used only self-reports of CWB and thus a cross-sectional self-report design overall. However, we replicated and extended the findings in Study 2 using supervisor-ratings of CWB.

Surprisingly, we did not observe any relation between one of the six HEXACO dimensions and CWB in Study 2. Indeed, a recent meta-analysis (Pletzer et al., 2019) found substantial $(>|.20|)$ sample-size weighted mean observed correlations between workplace deviance (which can be considered as CWB) and both HEXACO Honesty-Humility $(r=-.39)$ and Conscientiousness ( $r=-.33$; for similar meta-analytic findings, see Zettler et al., 2020). At the same time, most of the correlations among the HEXACO dimensions found in Study 2 are 
very much in line with the correlations found in a recent meta-analysis on the HEXACO-PI-R (Moshagen et al., 2019). So, one potential explanation is the use of two different rating sources in Study 2, namely, self-ratings for the HEXACO traits and supervisor-ratings for CWB. Indeed, Pletzer et al. (2019) reported that they did not find any study linking the HEXACO traits to other-ratings — let alone supervisor-ratings — of workplace deviance, so there are no findings to compare our results to. Further, Berry and colleagues (2012) reported substantial differences in meta-analytic links between the Big Five traits and self- vs. other-rated CWB (again, note that other-rated did not include supervisor ratings only). For instance, Big Five Emotional Stability was found to correlate with other-rated CWB $r=-.05$ in the meta-analysis by Berry et al. (2012), but -.23 with self-rated CWB in the meta-analysis by Berry and colleagues (2007), and Conscientiousness was found to correlate -.18 with other-rated CWB (Berry et al., 2012), but .31 with self-reported CWB (Berry et al., 2007). Researchers have frequently suggested that selfratings of CWB may capture a broader range of CWBs compared to supervisor ratings (e.g. Berry et al., 2012). A potential explanation of our findings could be that supervisor ratings include less respondent and more operant CWBs and were thus related to motives- but not traits-in Study 2. In contrast, self-ratings of CWB may include both operant and respondent behaviors which would explain that both implicit motives and traits were related to CWB in Study 1 . This explanation is relatively speculative, however, because we did not differentiate between operant and respondent types of CWB. Overall, we believe that the reliance on two different rating sources is a strength of Study 2, but we nonetheless emphasize that future research looking at the links between the HEXACO dimensions and CWB across rating sources is needed. 
The samples in both studies were from broad occupational backgrounds. It is unclear to what extent the observed effects can be generalized to a subsample with more specific jobs. Future research should study whether job contexts may influence the links between motives and CWB. For instance, in jobs with few social interactions, it seems plausible that the effect of the implicit Affiliation motive on CWB may be weaker.

\section{Conclusion}

Studying and understanding the antecedents of CWB is important because CWB can be costly for organizations (Marcus et al., 2016). One line of research has therefore studied individual difference variables as predictors of CWB (Salgado, 2002; Spector, 2011; Zettler, 2017). The present study contributes to this literature by examining the effects of the implicit Affiliation, Achievement, and Power motives on CWB. Overall, our findings support the idea that implicit motives predict CWB in addition to personality traits. In conclusion, we suggest that it may be beneficial for researchers studying CWB to consider implicit motives and more specifically the implicit Affiliation and the implicit Power motive. 


\section{References}

Allport, G. W. (1931). What is a trait of personality? Journal of Abnormal and Social Psychology, 25, 368-372.

Apers, C., Lang, J. W. B., \& Derous, E. (2018). Who earns more? Explicit traits, implicit motives and income growth trajectories. Journal of Vocational Behavior. https://doi.org/10.1016/J.JVB.2018.12.004

Ashton, M. C., \& Lee, K. (2007). Empirical, theoretical, and practical advantages of the HEXACO model of personality structure. Personality and Social Psychology Review, 11(2), 150-166. https://doi.org/10.1177/1088868306294907

Barrick, M. R., Mount, M. K., \& Li, N. (2013). The theory of purposeful work behavior: The role of personality, job characteristics, and experienced meaningfulness. Academy of Management Review, 38, 1-51. https://doi.org/10.5465/amr.2010.0479

Bennett, R. J., \& Robinson, S. L. (2000). Development of a measure of workplace deviance. Journal of Applied Psychology, 85, 349-360. https://doi.org/10.1037/0021-9010.85.3.349

Berry, C. M., Carpenter, N. C., \& Barratt, C. L. (2012). Do other-reports of counterproductive work behavior provide an incremental contribution over self-reports? A meta-analytic comparison. Journal of Applied Psychology, 97, 613-636. https://doi.org/10.1037/a0026739

Berry, C. M., Ones, D. S., \& Sackett, P. R. (2007). Interpersonal deviance, organizational deviance, and their common correlates: A review and meta-analysis. Journal of Applied Psychology, 92, 410-424. https://doi.org/10.1037/0021-9010.92.2.410

Bing, M. N., LeBreton, J. M., Davison, H. K., Migetz, D. Z., \& James, L. R. (2007). Integrating implicit and explicit social cognitions for enhanced personality assessment: A general framework for choosing measurement and statistical methods. Organizational Research Methods, 10, 136-179. https://doi.org/10.1177/1094428106289396 
Brunstein, J. C., \& Maier, G. W. (2005). Implicit and self-attributed motives to achieve: Two separate but interacting needs. Journal of Personality and Social Psychology, 89, 205-222. https://doi.org/10.1037/0022-3514.89.2.205

Brunstein, J. C., Schultheiss, O. C., \& Grässman, R. (1998). Personal goals and emotional wellbeing: the moderating role of motive dispositions. [JOUR]. Journal of Personality and Social Psychology, 75(2), 494.

Carver, C. S., \& Scheier, M. F. (1998). On the Self-Regulation of Behavior: https://doi.org/10.1017/CBO9781139174794

Cohen, J. (1988). Statistical Power Analysis for the Behavioral Sciences (2nd Ed.). Hillsdale, NJ: Laurence Erlbaum Associates.

Collins, J. M., \& Griffin, R. W. (1998). The psychology of counterproductive job performance. In R. W. Griffin, A. O’Leary-Kelly, \& J. M. Collins (Eds.), Dysfunctional behavior in organizations: Non-violent dysfunctional behavior. Monographs in organizational behavior and relations (pp. 219-242).

Coyne, I., Craig, J., \& Smith-Lee Chong, P. (2004). Workplace bullying in a group context. British Journal of Guidance \& Counselling, 32, 301-317. https://doi.org/10.1080/03069880410001723530

Cullen, M. J., \& Sackett, P. R. (2003). Personality and Counterproductive Workplace Behavior. In M. Barrick \& A. M. Ryan (Eds.), Personality and Work (pp. 150-182). New York: Jossey-Bass-Pfeiffer.

DeYoung, C. G. (2015). Cybernetic Big Five theory. Journal of Research in Personality, 56, 3358. https://doi.org/10.1016/j.jrp.2014.07.004

Dufner, M., Arslan, R. C., Hagemeyer, B., Schönbrodt, F. D., \& Denissen, J. J. A. (2015). 
Affective contingencies in the affiliative domain: Physiological assessment, associations with the affiliation motive, and prediction of behavior. Journal of Personality and Social Psychology, 109, 662-676. https://doi.org/10.1037/pspp0000025

Emmons, R. A. (1993). The current status of the motive concept. In K. H. Craik, R. Hogan, \& R. N. Wolfe (Eds.), Fifty years of personality psychology (pp. 187-196). New York: Plenum. Exline, R. V. (1962). Need affiliation and initial communication behavior in problem-solving groups characterized by low interpersonal visibility. Psychological Reports, 10, 79-89. https://doi.org/10.2466/pr0.1962.10.1.79

Farley, S. D. (2011). Is gossip power? The inverse relationships between gossip, power, and likability. European Journal of Social Psychology, 41, 574-579. https://doi.org/10.1002/ejsp.821

Fodor, E. M., \& Carver, R. A. (2000). Achievement and power motives, performance feedback, and creativity. Journal of Research in Personality, 34, 380-396. https://doi.org/10.1006/jrpe.2000.2289

Fodor, E. M., Wick, D. P., \& Hartsen, K. M. (2006). The power motive and affective response to assertiveness. Journal of Research in Personality, 40(5), 598-610. https://doi.org/10.1016/j.jrp.2005.06.001

Greco, L. M., O’Boyle, E. H., \& Walter, S. L. (2015). Absence of malice: A meta-analysis of nonresponse bias in counterproductive work behavior research. Journal of Applied Psychology, 100(1), 75-97. https://doi.org/10.1037/a0037495

Gröpel, P., \& Kehr, H. M. (2014). Motivation and self-control: Implicit motives moderate the exertion of self-control in motive-related tasks. Journal of Personality, 82(4), 317-328. https://doi.org/10.1111/jopy.12059 
Gwet, K. L. (2008a). Computing inter-rater reliability and its variance in the presence of high agreement. The British Journal of Mathematical and Statistical Psychology, 61, 29-48. https://doi.org/10.1348/000711006X126600

Gwet, K. L. (2008b). Variance estimation of nominal-scale inter-rater reliability with random selection of raters. Psychometrika, 73, 407-430. https://doi.org/10.1007/s11336-007-9054-8

Heckhausen, H., Schmalt, H. D., \& Schneider, K. (1985). Achievement motivation in perspective. New York: Academic Press.

Hershcovis, M. S., Turner, N., Barling, J., Arnold, K. A., Dupré, K. E., Inness, M., ... Sivanathan, N. (2007). Predicting workplace aggression: A meta-analysis. Journal of Applied Psychology, 92, 228-238. https://doi.org/10.1037/0021-9010.92.1.228

Hofer, J., Busch, H., Bond, M. H., Campos, D., Li, M., \& Law, R. (2010). The implicit power motive and sociosexuality in men and women: Pancultural effects of responsibility. Journal of Personality and Social Psychology, 99, 380-394. https://doi.org/10.1037/a0020053

Hogan, R., \& Kaiser, R. B. (2005). What we know about leadership. Review of General Psychology, 9, 169-180.

Hollinger, R. C., \& Davis, J. L. (2002). National retail security survey 2001. Gainesville.

House, R. J., \& Howell, J. M. (1992). Personality and charismatic leadership. The Leadership Quarterly, 3, 81-108. https://doi.org/10.1016/1048-9843(92)90028-E

House, R. J., Spangler, W. D., \& Woycke, J. (1991). Personality and charisma in the U.S. presidency: A psychological theory of leader effectiveness. Administrative Science Quarterly, 36, 364. https://doi.org/10.2307/2393201

James, L. R., \& LeBreton, J. M. (2012). Asessing the Implicit Personality Through Conditional Reasoning. Washington, DC: American Psychological Association. 
John, O. P., Naumann, L. P., \& Soto, C. J. (2008). Paradigm shift to the integrative Big Five trait taxonomy. In Oliver P. John, R. W. Robins, \& L. A. Pervin (Eds.), Handbook of Personality: Theory and Research (3rd ed., pp. 114-158). New York: The Guilford Press.

Kehr, H. M. (2004). Integrating implicit motives, explicit motives, and perceived abilities: The compensatory model of work motivation and volition. Academy of Management Review, 29, 479-499. https://doi.org/10.5465/AMR.2004.13670963

Koestner, R., \& McClelland, D. C. (1992). The affiliation motive. In C. P. Smith (Ed.), Motivation and personality: Handbook of thematic content analysis (pp. 205-210). Cambridge, MA: Cambridge University Press.

Kuhl, J. (2013). Auswertungsmanual für den Operanten Multi-Motiv-Test OMT [Coding Manual of the Operant Motive Test OMT]. Osnabrück, Germany: Impart GmbH.

Lang, J. W. B. (2014). A dynamic Thurstonian item response theory of motive expression in the picture story exercise: Solving the internal consistency paradox of the PSE. Psychological Review, 121, 481-500. https://doi.org/10.1037/a0037011

Lang, J. W. B., Zettler, I., Ewen, C., \& Hülsheger, U. R. (2012). Implicit motives, explicit traits, and task and contextual performance at work. Journal of Applied Psychology, 97, 12011217. https://doi.org/10.1037/a0029556

Langner, C. A., \& Winter, D. G. (2001). The motivational basis of concessions and compromise: archival and laboratory studies. Journal of Personality and Social Psychology, 81, 711-727. https://doi.org/http://dx.doi.org/10.1037/0022-3514.81.4.711

Lee, K., \& Ashton, M. C. (2018). Psychometric Properties of the HEXACO-100. Assessment, 25(5), 543-556. https://doi.org/10.1177/1073191116659134

Lievens, F., Chasteen, C. S., Day, E. A., \& Christiansen, N. D. (2006). Large-scale investigation 
of the role of trait activation theory for understanding assessment center convergent and discriminant validity. Journal of Applied Psychology, 91, 247-258.

https://doi.org/10.1037/0021-9010.91.2.247

Lord, R. G., Foti, R. J., \& De Vader, C. L. (1984). A test of leadership categorization theory: Internal structure, information processing, and leadership perceptions. Organizational Behavior and Human Performance, 34, 343-378. https://doi.org/10.1016/00305073(84)90043-6

Magee, J. C., \& Langner, C. A. (2008). How personalized and socialized power motivation facilitate antisocial and prosocial decision-making. Journal of Research in Personality, 42(6), 1547-1559. https://doi.org/10.1016/j.jrp.2008.07.009

Marcus, B., Lee, K., \& Ashton, M. C. (2007). Personality dimensions explaining relationships between integrity tests and counterproductive behavior: Big Five, or one in addition? Personnel Psychology, 60, 1-34.

Marcus, B., \& Schuler, H. (2004). Antecedents of Counterproductive Behavior at Work: A General Perspective. Journal of Applied Psychology, 89(4), 647-660. https://doi.org/10.1037/0021-9010.89.4.647

Marcus, B., Taylor, O. A., Hastings, S. E., Sturm, A., \& Weigelt, O. (2016). The structure of counterproductive work behavior. Journal of Management, 42, 203-233. https://doi.org/10.1177/0149206313503019

McAdams, D. P. (1997). A Conceptual History of Personality Psychology. Handbook of Personality Psychology, 3-39. https://doi.org/10.1016/B978-012134645-4/50002-0

McAdams, D. P., Jackson, R. J., \& Kirshnit, C. (1984). Looking, laughing, and smiling in dyads as a function of intimacy motivation and reciprocity. Journal of Personality, 52, 261-273. 
https://doi.org/10.1111/j.1467-6494.1984.tb00881.x

McAdams, D. P., \& Pals, J. L. (2006). A new Big Five: Fundamental principles for an integrative science of personality. American Psychologist, 61(3), 204-217. https://doi.org/10.1037/0003-066X.61.3.204

McClelland, D. C. (1970). The two faces of power. Journal of International Affairs, 24, 29 - 47.

McClelland, D. C. (1975). Power: The inner experience. New York: Wiley.

McClelland, D. C. (1984). Motives, personality, and society: Selected papers. New York, NY, NY: Praeger Publishers.

McClelland, D. C. (1985). Human motivation. Glenview, IL: Scott Foresman.

McClelland, D. C., Atkinson, J. W., Clark, R. A., \& Lowell, E. L. (1953). The measuring instrument. In The achievement motive (pp. 185-217). East Norwalk, CT, US: AppletonCentury-Crofts.

McClelland, D. C., Koestner, R., \& Weinberger, J. (1989). How do self-attributed and implicit motives differ? Psychological Review, 96, 690-702. https://doi.org/10.1037/0033295X.96.4.690

McCrae, R. R., \& John, O. P. (1992). An introduction to the Five-Factor Model and its applications. Journal of Personality, 60, 175-215. https://doi.org/10.1111/j.14676494.1992.tb00970.x

Mischel, W. (1968). Personality and assessment. New York: Wiley.

Mischel, W. (1973). Toward a cognitive social learning reconceptualization of personality. Psychological Review, 80(4), 252-283. https://doi.org/10.1037/h0035002

Morgan, C. D., \& Murray, H. A. (1935). A method for investigating fantasies: The Thematic Apperception Test. Archives of Neurology \& Psychiatry, 34, 289-306. 
https://doi.org/10.1001/archneurpsyc.1935.02250200049005

Moshagen, M., Thielmann, I., Hilbig, B. E., \& Zettler, I. (2019). Meta-Analytic Investigations of the HEXACO Personality Inventory(-Revised). Zeitschrift Für Psychologie, 227(3), 186194. https://doi.org/10.1027/2151-2604/a000377

Murray, H. A. (1938). Explorations in personality; A clinical and experimental study of fifty men of college age. https://doi.org/10.2307/2084329

Pellegrini, A. D., Bartini, M., \& Brooks, F. (1999). School bullies, victims, and aggressive victims: Factors relating to group affiliation and victimization in early adolescence. Journal of Educational Psychology, 91, 216-224. https://doi.org/10.1037/0022-0663.91.2.216

Pfaff, D. W. (1999). Drive: Neurobiological and molecular mechanisms of sexual motivation. Cambridge, MA: MIT Press.

Pfeffer, J. (1981). Power in orgaizations. Marshfield, MA: Pitman.

Pletzer, J. L., Bentvelzen, M., Oostrom, J. K., \& De Vries, R. E. (2019). A meta-analysis of the relations between personality and workplace deviance: Big Five versus HEXACO. Journal of Vocational Behavior, 112, 369-383. https://doi.org/10.1016/j.jvb.2019.04.004

Rauch, A., \& Frese, M. (2007). Let's put the person back into entrepreneurship research: A meta-analysis on the relationship between business owners' personality traits, business creation, and success. European Journal of Work and Organizational Psychology, 16, 353385. https://doi.org/10.1080/13594320701595438

Robinson, S. L., \& Bennett, R. J. (1995). A typology of deviant workplace behaviors: A multidimensional scaling study. Academy of Management Journal, 38, 555-572. https://doi.org/10.2307/256693

Robinson, S. L., \& Greenberg, J. (1998). Employees behaving badly: Dimensions, determinants 
and dilemmas in the study of workplace deviance. Journal of Organizational Behavior, 5, $1-30$.

Runge, J. M., \& Lang, J. W. B. (2019). Can people recognize their implicit thoughts? The motive self-categorization test. Psychological Assessment. https://doi.org/10.1037/pas0000720

Runge, J. M., Lang, J. W. B., Chasiotis, A., \& Hofer, J. (2019). Improving the Assessment of Implicit Motives Using IRT: Cultural Differences and Differential Item Functioning. Journal of Personality Assessment, 101(4). https://doi.org/10.1080/00223891.2017.1418748

Runge, J. M., Lang, J. W. B., Engeser, S., Schüler, J., den Hartog, S. C. S. C., \& Zettler, I. (2016). Modeling motive activation in the operant motives test: A psychometric analysis using dynamic Thurstonian item response theory. Motivation Science, 2, 268-286. https://doi.org/10.1037/mot0000041

Salgado, J. F. (2002). The Big Five personality dimensions and counterproductive behaviors. International Journal of Selection and Assessment, 10, 117-125. https://doi.org/10.1111/1468-2389.00198

Schüler, J., Brandstätter, V., Wegner, M., \& Baumann, N. (2015). Testing the convergent and discriminant validity of three implicit motive measures: PSE, OMT, and MMG. Motivation and Emotion, 39, 839-857. https://doi.org/10.1007/s11031-015-9502-1

Schultheiss, O. C. (2013). Are implicit motives revealed in mere words? Testing the markerword hypothesis with computer-based text analysis. Frontiers in Psychology, 4, 748. https://doi.org/10.3389/fpsyg.2013.00748

Schultheiss, O. C., \& Brunstein, J. (2010). Implicit Motives. In O. P. John, R. W. Robins, \& L. A. Pervin (Eds.), Handbook of personality: Theory and research (3rd ed., pp. 603-633). https://doi.org/10.1093/acprof:oso/9780195335156.001.0001 
Schultheiss, O. C., Jones, N. M., Davis, A. Q., \& Kley, C. (2008). The role of implicit motivation in hot and cold goal pursuit: Effects on goal progress, goal rumination, and emotional wellbeing. Journal of Research in Personality, 42(4), 971-987.

https://doi.org/10.1016/j.jrp.2007.12.009

Smith, C. P. (1992). Motivation and personality: Handbook of thematic content analysis. New York: Cambridge University Press.

Spangler, W. D. (1992). Validity of questionnaire and TAT measures of need for achievement: Two meta-analyses. Psychological Bulletin, 112, 140-154. https://doi.org/10.1037/00332909.112.1.140

Spangler, W. D., Kim, J., Sotak, K. L., \& Marshall, J. (2019). Implicit motives for achievement, power, and affiliation are internal states that energize and direct behavior. Academy of Management Annual Meeting, 38.

Spangler, W. D., Tikhomirov, A., Sotak, K. L., \& Palrecha, R. (2014, December 1). Leader motive profiles in eight types of organizations. Leadership Quarterly, Vol. 25, pp. 10801094. https://doi.org/10.1016/j.leaqua.2014.10.001

Spector, P. E. (2011). The relationship of personality to counterproductive work behavior (CWB): An integration of perspectives. Human Resource Management Review, 21, 342352. https://doi.org/10.1016/j.hrmr.2010.10.002

Spector, P. E., \& Fox, S. (2005). A model of counterproductive work behavior. In S. Fox \& P. E. Spector (Eds.), Counterproductive workplace behavior: Investigations of actors and targets (pp. 151-174). Washington, DC: APA.

Stanton, S. J., Hall, J. L., \& Schultheiss, O. C. (2010). Properties of motive-specific incentives. In O. C. Schultheiss \& J. C. Brunstein (Eds.), Implicit Motives (pp. 245-278). New York, 
NY: Oxford University Press.

Toates, F. (1986). Motivational systems. Cambridge, GB: Cambridge University Press.

Uhlmann, E. L., Leavitt, K., Menges, J. I., Koopman, J., Howe, M., \& Johnson, R. E. (2012).

Getting explicit about the implicit: A taxonomy of implicit measures and guide for their use in organizational research. Organizational Research Methods, 15, 553-601. https://doi.org/10.1177/1094428112442750

Wainer, H. A., \& Rubin, I. M. (1969). Motivation of research and development entrepreneurs: Determinants of company success. Journal of Applied Psychology, 53, 178-184.

Walker, E. L., \& Heyns, R. N. (1962). An anatomy for conformity. Eaglewood Cliffs, NJ: Prentice-Hall.

Weinberger, J., \& McClelland, D. C. (1990). Cognitive versus traditional motivational models: Irreconcilable or complementary? In E. T. Higgins \& R. M. Sorrentino (Eds.), Handbook of motivation and cognition: Foundations of social Behavior (Vol. 2, pp. 562-597). New York: Guilford Press.

Winter, D. G. (1973). The power motive. New York, NY, US: Free Press.

Winter, D. G. (1994). Manual for scoring motive imagery in running text. Ann Arbor: University of Michigan.

Winter, D. G. (2016). Taming power: Generative historical consciousness. American Psychologist, 71, 161-174. https://doi.org/10.1037/a0039312

Winter, D. G., John, O. P., Stewart, A. J., Klohnen, E. C., \& Duncan, L. E. (1998). Traits and motives: Toward an integration of two traditions in personality research. Psychological Review, 105, 230-250. https://doi.org/10.1037/0033-295X.105.2.230

Winter, D. G., McClelland, D. C., \& Stewart, A. J. (1981). A new case for the liberal arts. 
Assessing institutional goals and student development. Jossey-Bass.

Wrzesniewski, A., Dutton, J. E., \& Debebe, G. (2003). Interpersonal sensemaking and the meaning of work. Research in Organizational Behavior, 25, 93-135. https://doi.org/10.1016/S0191-3085(03)25003-6

Yukl, G., \& Falbe, C. M. (1991). Importance of different power sources in downward and lateral relations. Journal of Applied Psychology, 76, 416-423. https://doi.org/10.1037/00219010.76 .3 .416

Zettler, I. (2017). Personality and Counterproductive Work Behavior. In Encyclopedia of Personality and Individual Differences. Springer International Publishing.

Zettler, I., \& Hilbig, B. E. (2010). Honesty-humility and a person-situation interaction at work. European Journal of Personality, 24, 569-582. https://doi.org/10.1002/per.757

Zettler, I., Thielmann, I., Hilbig, B. E., \& Moshagen, M. (2020). The Nomological Net of the HEXACO Model of Personality: A Large-Scale Meta-Analytic Investigation. Perspectives on Psychological Science, 15(3), 723-760. https://doi.org/10.1177/1745691619895036

Zurbriggen, E. L. (2000). Social motives and cognitive power-sex associations: Predictors of aggressive sexual behavior. Journal of Personality and Social Psychology, 78(3), 559-581. https://doi.org/10.1037/0022-3514.78.3.559 


\section{Table 1}

Means, Standard Deviations, and Intercorrelations of the Variables in Study 1

\begin{tabular}{|c|c|c|c|c|c|c|c|c|c|c|}
\hline Construct & $M$ & $S D$ & 1. & 2. & 3. & 4. & 5. & 6. & 7. & 8. \\
\hline 1. Extraversion & 3.65 & 0.65 & & & & & & & & \\
\hline 2. Conscientiousness & 3.85 & 0.56 & $.21 * *$ & & & & & & & \\
\hline 3. Agreeableness & 3.63 & 0.48 & -.09 & .06 & & & & & & \\
\hline 4. Neuroticism & 2.78 & 0.64 & $-.13 *$ & $-.23 * *$ & $-.26 * *$ & & & & & \\
\hline 5. Openness & 3.51 & 0.53 & $.38 * *$ & .07 & .04 & -.11 & & & & \\
\hline 6. Affiliation & 0.12 & 0.08 & .02 & .02 & .09 & -.01 & -.03 & & & \\
\hline 7. Power & 0.38 & 0.14 & .01 & .05 & .06 & -.04 & -.05 & $-.43 * *$ & & \\
\hline 8. Achievement & 0.14 & 0.07 & .08 & .10 & .03 & $-.14^{*}$ & $.18 * *$ & .04 & $-.14 *$ & \\
\hline 9. CWB & 1.80 & 0.57 & .03 & $-.29 * *$ & $-.25 * *$ & .05 & .10 & $-.20 * *$ & -.00 & .07 \\
\hline
\end{tabular}

Note. Study 1: $N=$ 263. $M=$ mean, $S D=$ standard deviation, $\mathrm{CWB}=$ Counterproductive Work Behavior.

$* p<.05 ; * * p<.01$ 
Table 2

Regression Analyses Predicting Counterproductive Work Behavior with Implicit Motives and Explicit Traits

\begin{tabular}{|c|c|c|c|c|c|c|c|c|c|}
\hline \multirow[b]{2}{*}{ Parameter } & \multicolumn{3}{|c|}{ Model 1} & \multicolumn{3}{|c|}{ Model 2} & \multicolumn{3}{|c|}{ Model 3} \\
\hline & Est. & $t$ & $B$ & Est. & $t$ & B & Est. & $t$ & B \\
\hline & & & & tudy 1 & & & & & \\
\hline \multicolumn{10}{|l|}{ Coefficients $(b)$} \\
\hline Intercept & 3.74 & $7.67 *$ & & 2.11 & $12.63^{*}$ & & 3.84 & $7.80 *$ & \\
\hline Extraversion & 0.02 & 0.36 & .02 & & & & 0.03 & 0.56 & .04 \\
\hline Conscientiousness & -0.31 & $-5.15^{*}$ & -.31 & & & & -0.31 & $-5.24 *$ & -.31 \\
\hline Agreeableness & -0.29 & $-4.16^{*}$ & -.25 & & & & -0.27 & $-3.80^{*}$ & -.23 \\
\hline Neuroticism & -0.06 & -1.14 & -.07 & & & & -0.05 & -0.95 & -.06 \\
\hline Openness & 0.12 & 1.81 & .11 & & & & 0.09 & 1.39 & .09 \\
\hline Affiliation & & & & -1.82 & $-3.67 *$ & -.25 & -1.45 & $-3.12^{*}$ & -.20 \\
\hline Power & & & & -0.40 & -1.48 & -.10 & -0.19 & -0.75 & -.05 \\
\hline Achievement & & & & 0.52 & 1.06 & .06 & 0.64 & 1.38 & .08 \\
\hline$R^{2}$ & .16 & & & .05 & & & .20 & & \\
\hline$F$ & $9.73 *$ & & & $4.92 *$ & & & $7.81 *$ & & \\
\hline$\Delta R^{2}$ vs. Model 1 & & & & & & & .04 & & \\
\hline$\Delta F^{2}$ vs. Model 1 & & & & & & & $4.02 *$ & & \\
\hline & & & & tudy 2 & & & & & \\
\hline \multicolumn{10}{|l|}{ Coefficients $(b)$} \\
\hline Intercept & 0.95 & 1.68 & & 1.72 & $13.01 *$ & & 1.23 & $2.22 *$ & \\
\hline Honesty-humility & -0.05 & -0.63 & -.07 & & & & -0.06 & -0.71 & -.07 \\
\hline Emotionality & 0.04 & 0.55 & .05 & & & & 0.04 & 0.57 & .05 \\
\hline Extraversion & -0.01 & -0.08 & -.01 & & & & -0.01 & -0.09 & -.01 \\
\hline Agreeableness & 0.12 & 1.46 & .14 & & & & 0.15 & 1.79 & .18 \\
\hline Conscientiousness & 0.00 & -0.01 & .00 & & & & 0.01 & 0.09 & .01 \\
\hline Openness & 0.03 & 0.45 & .04 & & & & 0.05 & 0.69 & .07 \\
\hline Affiliation & & & & -0.89 & $-2.05^{*}$ & -.19 & -0.95 & $-2.16^{*}$ & -.20 \\
\hline Power & & & & -0.68 & $-2.21 *$ & -.20 & -0.73 & $-2.29 *$ & -.22 \\
\hline Achievement & & & & -0.72 & -1.60 & -.15 & -0.79 & -1.74 & -.16 \\
\hline$R^{2}$ & .02 & & & .08 & & & .11 & & \\
\hline$F$ & 0.43 & & & $3.37 *$ & & & 1.56 & & \\
\hline$\Delta R^{2}$ vs. Model 1 & & & & & & & .09 & & \\
\hline$\Delta F^{2}$ vs. Model 1 & & & & & & & $3.75 *$ & & \\
\hline
\end{tabular}

Note. Study 1: $N=263$. Study 2: $N=121$. Est. = Estimate. To get standard errors for the $b$ and $B$ coefficients, divide the $b$ and $B$ coefficients by the $t$ values. dfs Study 1: Model $1=257$, Model $2=259$, and Model $3=254$; dfs Study 2: Model $1=114$, Model $2=117$, and Model $3=111$.

$* p<.05$. 


\section{Table 3}

Means, Standard Deviations, and Intercorrelations of the Variables in Study 2

\begin{tabular}{|c|c|c|c|c|c|c|c|c|c|c|c|}
\hline Measure & $M$ & $S D$ & 1 & 2 & 3 & 4 & 5 & 6 & 7 & 8 & 9 \\
\hline 1. Honesty-humility & 3.66 & 0.53 & & & & & & & & & \\
\hline 2. Emotionality & 3.22 & 0.56 & -.05 & & & & & & & & \\
\hline 3. Extraversion & 3.74 & 0.46 & -.12 & -.06 & & & & & & & \\
\hline 4. Agreeableness & 2.95 & 0.50 & $.37 * *$ & -.07 & .11 & & & & & & \\
\hline 5. Conscientiousness & 3.70 & 0.45 & .05 & .17 & .16 & .12 & & & & & \\
\hline 6. Openness & 3.35 & 0.55 & $.27 * *$ & -.07 & .16 & .12 & .06 & & & & \\
\hline 7. Affiliation & 0.12 & 0.09 & -.00 & .00 & .02 & .07 & -.06 & -.00 & & & \\
\hline 8. Power & 0.27 & 0.12 & .06 & -.00 & .05 & .05 & .15 & .04 & -.17 & & \\
\hline 9. Achievement & 0.14 & 0.09 & -.02 & -.01 & -.04 & .04 & -.05 & .11 & .16 & $-.24 * *$ & \\
\hline 10. CWB & 1.33 & 0.42 & -.00 & .04 & .02 & .12 & .02 & .04 & $-.18 *$ & -.14 & -.13 \\
\hline
\end{tabular}

Note. Study 2: $N=121 . M$ and $S D$ are used to represent mean and standard deviation, respectively. CWB $=$ Counterproductive Work Behavior.

$* p<.05 ; * * p<.01$ 


\section{Appendix}

\begin{tabular}{lrr}
\hline \multicolumn{1}{c}{ Job description } & Study 1 & Study 2 \\
\hline Physicians and nurses & 29 & 13 \\
Clerks & 45 & 25 \\
Human resource management & & 5 \\
Social workers & 5 & 8 \\
Engineers or technicians & 20 & 13 \\
Managers & 7 & 3 \\
Sales & 18 & 4 \\
Business consultants & 7 & 5 \\
Personnel training & 6 & 2 \\
College teachers or instructors & 9 & 2 \\
Banking and financial & 7 & 2 \\
Dentist/support personnel & 4 & 1 \\
Pharmacist & 5 & 4 \\
Optician & 21 & 1 \\
School or kindergarten teacher & 37 & 1 \\
Lawyers & 2 & \\
Carpenter & & 1 \\
Public administration & 15 & \\
Tax accountants & 4 & \\
Level in the organizational hierarchy & 13 & 21 \\
Not filled out & & 10 \\
\hline
\end{tabular}

